\title{
Evaluating the economic impact of national sporting performance: Evidence from the Johannesburg Stock Exchange
}

\author{
B.K. Smith and J.D. Krige* \\ University of Stellenbosch Business School, \\ PO Box 610, Bellville 7535, Republic of South Africa \\ jdkrige@sun.ac.za
}

Received April 2010

\begin{abstract}
This study examines the impact of South Africa's national soccer, rugby and cricket teams' performances in international matches on returns on the Johannesburg Stock Exchange (JSE). Match results constitute a mood proxy variable hypothesised to affect stock returns through its influence on investor mood. The unconditional mean return on the JSE All Share index for a 13/2 year period from September 1995 to February 2009 was compared to the mean return after wins, draws and losses by the national sport teams. An event study approach was followed and four different statistical tests were conducted in order to test for a relationship. The results of the tests indicate the existence of a moderate win effect, with mean returns after wins being statistically significantly higher for the categories all sports combined, cricket and soccer.
\end{abstract}

*To whom all correspondence should be addressed.

\section{Introduction}

In recent times a number of studies have been conducted internationally in order to ascertain the economic impact of national sporting events. The majority of these studies have attempted to determine whether there is any causal relationship between the performance of national sports teams and stock prices on the local stock exchange. To date, the findings of these studies have provided mixed results with certain studies finding a strong relationship between national sporting team performance and stock price movements, whilst others finding no relationship that can be considered statistically significant. Although sport has increasingly become of greater economic relevance, rational investors would not be expected to be influenced by the outcome of a sporting event in terms of its effect on stock prices. However, the increasingly significant field of behavioural finance indicates that investors may indeed be influenced by non-economic factors that result in a change in an investor's mood. An increase or decrease in investor mood states as a result of national sporting performance is therefore hypothesised to reflect in stock prices. Hirt, Zillman, Erikson and Kennedy (1992) find that individuals' estimates of their own future abilities are positively correlated with sporting team success. Boyle and Walter (2003) state that this is primarily a result of changes in selfesteem resulting from success or failure, rather than in changes in mood per se. Boyle and Walter (2003) state that if sporting event outcomes do indeed influence investor selfesteem, they may therefore also influence investor behaviour in terms of changing personal beliefs about the investors' ability to identify successful investments. Positive sporting outcomes result in an increase in confidence and an increased willingness to make new investments. Conversely, negative sporting outcomes result in lower self-confidence and a decreased willingness to take on new investments. Boyle and Walter (2003) point out that in order to effectively examine the possibility that investors may react to sporting outcomes, sporting events are required where the majority of market participants support the same team. Without this, the psychological impact of sporting results would be cancelled out by opposing fans as one team's victory would by definition mean another team's defeat. For this reason the focus of this research report will be on international sporting contests involving South African sports teams and not domestic sporting events.

This research report builds on previous studies which have examined the effect of various national sport team performances on local stock exchanges. One of the first studies of this nature by Ashton, Gerrard and Hudson (2003) found a strong association between the performance of the England football (soccer) team and daily changes in the FTSE 100 index on the London Stock Exchange. The study found that positive performance (wins) by the national team led to positive performance of the index whilst negative performance (losses) led to negative performance of the index. Shortly thereafter, Boyle and Walter (2003) studied the impact of the New Zealand national rugby team (All Blacks) on the New Zealand national stock exchange, but concluded that no relationship existed. Edmans, Garcia and Norli (2007) studied football as well as a broader crosssection of sports throughout Europe, including rugby, basketball and cricket. As with the Ashton et al. (2003) study, their study found a positive relationship between losses and negative returns, which they called a "loss effect". However, it found no relationship between wins and positive returns. Lastly, Mishra and Smyth (2008) examined the impact of India's performance in one-day international cricket matches on the Indian stock exchange. The results suggested that the performance of the Indian team strongly affected returns on the Indian stock market. This research report aims to replicate the previous studies from a South African perspective. The main focus of the study will be on 
South Africa's three dominant sporting codes of soccer, rugby and cricket. South Africa regularly competes in international matches in all three sports and these are the sports that are of greatest national interest. An additional reason for choosing these three sports is that their supporters each have a unique demographic profile which could impact on the effect that mood changes resulting from team performance have on stock prices.

In order to determine whether a relationship exists between national sports results and daily stock price movements an event study was conducted. Sports results for the period under study were obtained from various sources and the first trading day after matches was determined. The match outcomes were divided into the result classifications of "win", "draw" and "loss". This was done for each sport category of cricket, soccer and rugby individually, as well as all sports combined. The mean daily return on the JSE All Share Index on the first trading day after matches was calculated and compared with the mean daily return for nongame trading days. Statistical analysis of the data was performed using a number of techniques used in previous studies. The rationale for using multiple analysis techniques was to allow for a comparison of the results with a broad number of similar studies. Two parametric tests were conducted assuming normally distributed data. The first investigated the relationship between the frequency (proportion) of daily market returns that were greater than or less than the mean return for non-game trading days, using $Z$-tests for the difference in proportions. The second parametric test examined the relationship between the mean daily market returns after matches and the mean daily return for non-game trading days, using $t$-tests for the difference in means. A dummy-variable regression analysis was also conducted. Finally, a non-parametric test was conducted using the Kruskal-Wallis $H$-test for the difference between two populations.

The remainder of this paper is organized as follows: a brief literature review is discussed in Section 2, followed by a review of the data and methodology in Section 3. The results are discussed in Section 4. A number of conclusions are discussed in Section 5, followed by a discussion of the limitations and constraints of this study in Section 6.

\section{Literature review}

Fock, Klein and Zwergel (2008) highlight the undeniable economic influence of sport. They give as an example the soccer World Cup held in Germany in 2006, which attracted over 4 million foreign fans that came to watch their national teams. The era of professional sport certainly has increased its economic significance, with many teams now even being listed on stock exchanges. Sponsorship, advertising and retail sales of sports clothing and equipment have also become a huge worldwide industry worth billions of dollars. Recent studies have begun to investigate the economic effect of sport from the point of view of its influence on financial decision makers.

Ashton et al. (2003) indicate two possible reasons why stock markets may react to sporting performance of national teams. Firstly, they identify a feel-good factor that results from national sporting success and that engenders greater confidence about the future. This can be described as an increase in positive affect (mood) in the general population as well as individuals. Secondly, they identify the increasing importance of international tournaments and increasing commercialisation of sport and sponsorship. An efficient stock market will therefore revise expectations of potential economic benefits of national sporting performance in the light of individual match results. Their study concludes that the sport industry can have a substantial influence on the wider economy but does not conclude whether this is due to the first or second factor.

Edmans et al. (2007) state that international soccer matches have particularly attractive properties as a measure of mood due to the fact that soccer is of national interest in most of the countries in which the study was conducted. The study points out that international soccer matches are unique in that there are few other regular events that can result in such a substantial change of mood of a large proportion of a country's population. The study, which uses a cross-section of 39 countries, finds a statistically significant negative effect on the losing country's stock market. The size of the "loss effect" is economically significant. In monthly terms the lower returns associated with a soccer loss exceed $7 \%$. The study also finds that the "loss effect" is stronger for small stocks and for more important matches. The hypothesised reason for a stronger effect for small stocks is that private investors are more likely to hold small stocks than larger stocks. This implies that mood changes caused by a country's performance in an international match are more likely to influence private investors than institutional investors. The study also documents a "loss effect" for international cricket, rugby and basketball games, although not as prominent as the "loss effect" for international soccer games. The authors claim that the results of the study are robust to methodological changes and conclude that the "loss effect" is caused by changes in investor moods. Interestingly, the results of the study by Edmans et al. (2007) differ from the results of the study by Ashton et al. (2003) in that there is no evidence of a corresponding reaction to wins in any of the sports studied. Edmans et al. (2007) postulate that this is due to the fact that sports fans tend to have unrealistic expectations of their team's performance. In many of the countries in which the study was conducted the national team is often expected to win. A loss therefore creates a much greater negative change in mood than a win would create a positive change in mood. If they are correct, it would explain the existence of a "loss effect" and the absence of a "win effect".

In another study Berument, Ceylan and Gozpinar (2006) investigate the effect of soccer success for three major Turkish soccer teams (Beşiktaş, Fenerbahçe and Galatasaray) on stock market returns. The results presented in their study suggest that a win for Beşiktaş against foreign rivals increases stock market returns. However, the same effect is not found for the other teams. In another Turkish study, Berument and Yucel (2005) find a connection between the success of the Turkish football team Fenerbahçe and the performance of Turkish industrial production. In the study, success by the national football team is treated as a proxy for industrial workers' mood and 
morale. The study finds that the monthly industrial growth rate increased by $0,26 \%$ with each game won by the team in European Cup matches.

Studies in other parts of the world have also shown the economic significance of sporting events. Kaplanski and Levy (2008), inspired by the work of Edmans et al. (2007), investigate the effect of the Soccer World Cup on US stock returns and find that mean returns over the period of World Cups was $-2,58 \%$ compared to a mean return of $1,21 \%$ for all other days over the same length of period. In another study conducted in the US, Krueger and Kennedy (1990) investigate the apparently well-known Super Bowl Stock Market Predictor (SB SMP) which asserts that the league affiliation of the winner is a close predictor of stock market direction. Krueger and Kennedy (1990) explain that if the Super Bowl is won by any team from the American Football League, then the market will finish the year lower than it started. However, if the Bowl is won by a team from the National Football League, the stock market will finish the year higher than it started. The results of their study show that an investment strategy over the 21 year period investigated using the SB SMP would have provided an investor with superior returns compared with a buy-and-hold strategy. Krueger and Kennedy (1990) struggle to explain the phenomenon, but propose the possibility that the phenomenon exists because a sufficient number of investors actually believe in it and it becomes a self-fulfilling prophecy. In another example of the economic effect of sport, Worthington (2007) examines the effect of the Melbourne Cup horse race on stock returns and finds that the mean Melbourne Cup day return is significantly higher than the mean return for other days in the year. The Melbourne Cup is Australia's premier horse race and one of the leading races in the world. Furthermore, the day that the race is run is unofficially regarded as Australia's national day. Worthington (2007) suggests that the exuberance and euphoria associated with this day are reflected in investor decision making, leading to greater positive returns than at any other time of the year.

All the studies discussed, other than that of Boyle and Walter (2003), find that sport has a significant economic effect through its effect on investor moods and therefore stock returns. However, in response to the study by Ashton et al. (2003) Fock et al. (2008) argue that empirical studies revealing stock return anomalies should be analysed more carefully and therefore endorse the use of replication studies in order to verify the results. Rebuilding the study of Ashton et al. (2003), they claim to be able to detect mistakes in the methodology of the study and suggest that even minor flaws in methodology can significantly influence the results of such studies. After replicating the study, the authors arrive at results that differ from those reported by Ashton et al. (2003). As suggested by Fock et al. (2008) it is therefore important that studies revealing stock return anomalies be scrutinized and replicated so as to confirm or refute their findings.

\section{Data and methodology}

In order to determine the existence and extent of any impact

of sporting results on the Johannesburg Stock Exchange
(JSE), daily data on the JSE All Share index (J203) from 4 September 1995 to 2 February 2009 was collected. The data was obtained from McGregor BFA (2009). All international cricket, soccer and rugby match results were collected for the same period. Cricket results were obtained from CricketArchive (2009) which contains detailed information regarding every cricket match played by the Proteas during the period of interest. In contrast to Mishra and Smyth (2008), who considered only one-day international matches, this study considered all three forms of cricket, including tests and twenty-twenty matches. Soccer results were obtained from the South African Football Association (SAFA) (2009). Detailed match results and statistics are available for all matches played by Bafana Bafana during the period of interest. Rugby results were obtained from Springbok Rugby Hall of Fame (SA Rugby, 2009). Detailed match results and statistics are available for all matches played by the Springboks for the period of interest. Figure 1 shows the sports results for each category of sport and result classification over the period of interest.

Match outcomes were divided into the results classifications of win, draw and loss and this was done individually for each sport category of cricket, soccer and rugby, as well as a category for all sports combined. In order to measure the impact of a team's performance on stock returns, the daily return of the All Share index on the first trading day immediately following a match was identified. Although the outcome of a match may be known during the course of a particular day, the first trading day immediately following the match was used. This ensured that returns for a particular day reflected a full day's trading and allowed for easier comparison. It often happens that more than one match is played prior to the next trading day. For example, over a weekend, there may be matches played by all three sports teams. This means that the first trading day after each match will be the Monday after the weekend and therefore it is the same for each sport. If the result of each match was different, for example a win in one sport and a loss in another, the observations were removed from the data. If the result of the outcome was the same for all categories of sport the observation was retained. This adjustment was quite substantial and accounted for $17 \%$ of the population of observations.

Following Mishra and Smyth (2008), the daily index returns were calculated using the following standard formula:

$\mathrm{R}_{\mathrm{t}}=\ln \left(\frac{\mathrm{P}_{\mathrm{t}}}{\mathrm{P}_{\mathrm{t}-1}}\right) \times 100$

where

$\mathrm{R}_{\mathrm{t}}$ represents the $\log$ return (continuously compounded return) for the market index, $P_{t}$ represents the closing index value at the end of the trading day and $P_{t-1}$ represents the closing index value at the end of the previous trading day. 


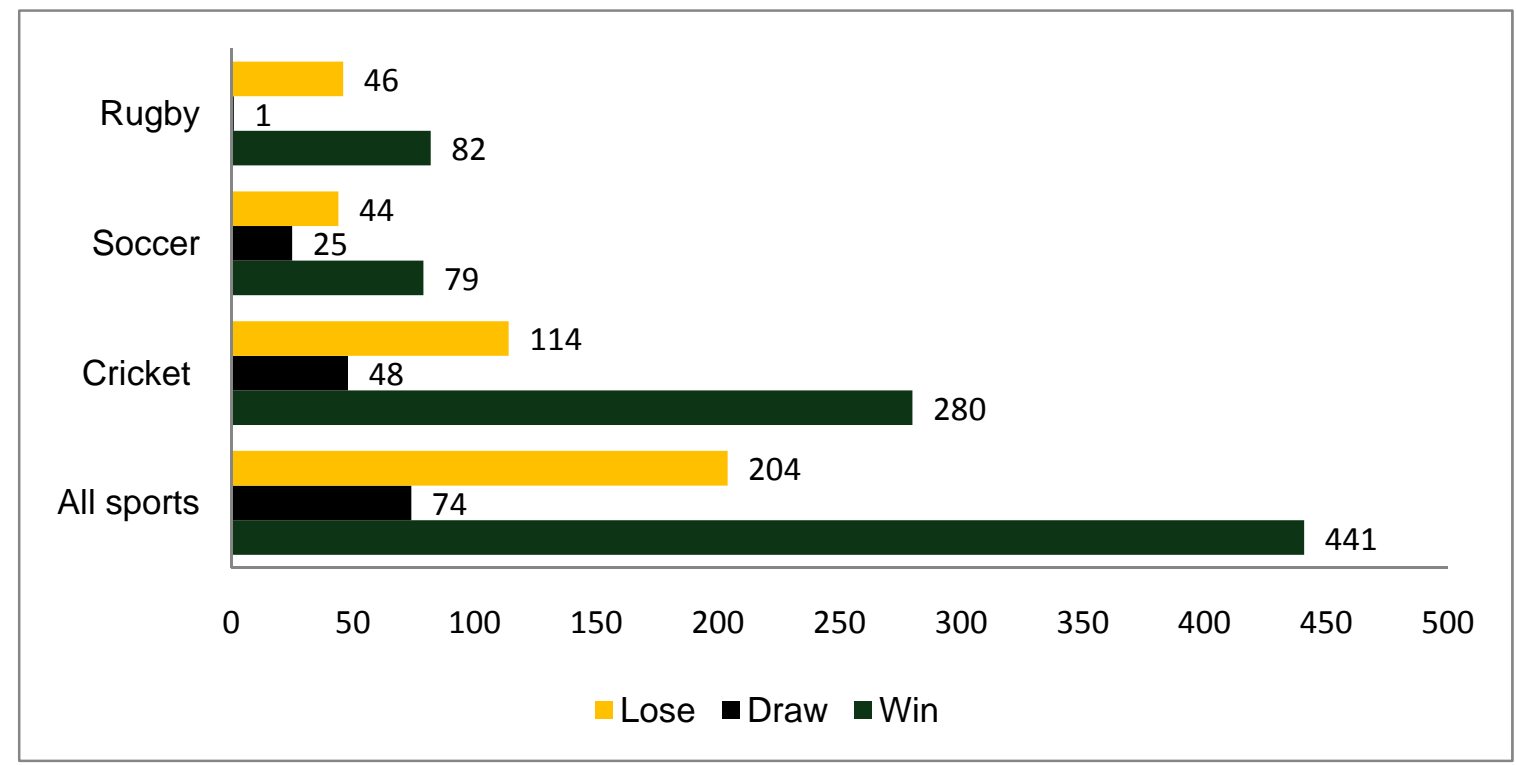

Figure 1: Sports results by category and result classification

Once the daily returns had been calculated the descriptive statistics were calculated for the daily returns for non-game trading days and for each category and classification of sport using Microsoft Excel's Data Analysis function. A summary of these statistics is provided in Table 1.

Lucey (2000) indicates that it is generally well accepted that security returns do not follow a normal distribution. However, despite this it is still the tendency of most authors to rely on standard classic statistical techniques assuming normality of the data distribution. Figure 2 shows the distribution of returns of the All Share index for the entire population of trading days for the period of study.

From Figure 2 and the data in Table 1 it is clear that the data indicates moderate skewness $(-0,3838)$ and kurtosis $(5,946)$. The fact that the distribution of returns is moderately negatively skewed suggests that the data is not normally distributed. In addition, kurtosis for a standard normal distribution is 3 and the data therefore confirms that it is not normally distributed.

The objective of this study was to investigate the relationship between national sporting team performance and stock returns in a South African context. For this purpose a similar approach was followed to those applied by Ashton et al. (2003), Boyle and Walter (2003), Edmans et al. (2007), and Mishra and Smyth (2008). Each of these studies used an event study methodology to investigate the relationship between the performance of various national sports teams and stock returns in their respective markets. However, a variety of statistical techniques were used by the different researchers. The rationale for using multiple techniques in this research report was therefore to enable the comparison of the results of this research report with previous studies. In addition, the use of multiple techniques ensured the robustness of the data and excluded the possibility of using a single approach that could be biased toward a particular result.
In order to determine if there is a relationship between sport team performance and returns on the JSE, the unconditional mean return for non-game trading days was compared to the mean return on the first trading day after matches in each category of sport and result classification.

The following statistical techniques were conducted for all sport categories and results classifications:

\section{$Z$-test for the difference in proportions}

Two parametric tests were conducted assuming normally distributed data. The first investigated the relationship between the frequency (proportion) of daily market returns after matches that are greater than or less than the mean return for non-game trading days. For this purpose the Z-test for the difference in proportions was used. This is the same approach as followed by Ashton et al. (2003).

\section{$t$-test for the difference in means}

The second parametric test examined the relationship between the mean daily market returns after matches and the mean daily return for non-game trading days, using the $t$-test for the difference in means. This is the same approach as followed by Boyle and Walter (2003).

\section{Dummy-variable regression analysis}

A dummy-variable regression analysis was conducted following the econometric approach of Edmans et al. (2007) and Mishra and Smyth (2008). Mishra and Smyth (2008) state that dummy-variable regression is an efficient method of separating the effects of events on stock returns. The following regression model was specified: 
Table 1: Summary statistics of returns

\begin{tabular}{|c|c|c|c|c|c|}
\hline & Number & Mean (\%) & St. Dev. & Skewness & Kurtosis \\
\hline All trading days & 3357 & 0,0516 & 1,323 & $-0,3838$ & 5,946 \\
\hline Non-game trading days & 2653 & 0,0572 & 1,293 & $-0,0787$ & 4,274 \\
\hline All matches & 720 & 0,073 & 1,450 & $-1,254$ & 11,298 \\
\hline All sports wins & 441 & 0,115 & 1,598 & $-1,577$ & 11,883 \\
\hline All sports draws & 74 & 0,082 & 1,365 & 0,948 & 4,208 \\
\hline All sports losses & 204 & 0,006 & 1,074 & $-0,563$ & 2,620 \\
\hline Cricket wins & 280 & 0,083 & 1,772 & $-1,807$ & 11,871 \\
\hline Cricket draws & 48 & $-0,174$ & 1,082 & $-0,984$ & 1,466 \\
\hline Cricket losses & 114 & $-0,015$ & 1,158 & $-0,881$ & 3,068 \\
\hline Soccer wins & 79 & 0,277 & 1,200 & 0,063 & 0,195 \\
\hline Soccer draws & 25 & 0,597 & 1,719 & 1,410 & 2,276 \\
\hline Soccer losses & 44 & 0,130 & 1,004 & 0,613 & 1,132 \\
\hline Rugby wins & 82 & 0,065 & 1,277 & 0,048 & 2,585 \\
\hline Rugby draws & 1 & $-0,459$ & $\mathrm{n} / \mathrm{a}$ & $\mathrm{n} / \mathrm{a}$ & $\mathrm{n} / \mathrm{a}$ \\
\hline Rugby losses & 46 & $-0,058$ & 0,924 & $-0,369$ & 0,310 \\
\hline
\end{tabular}

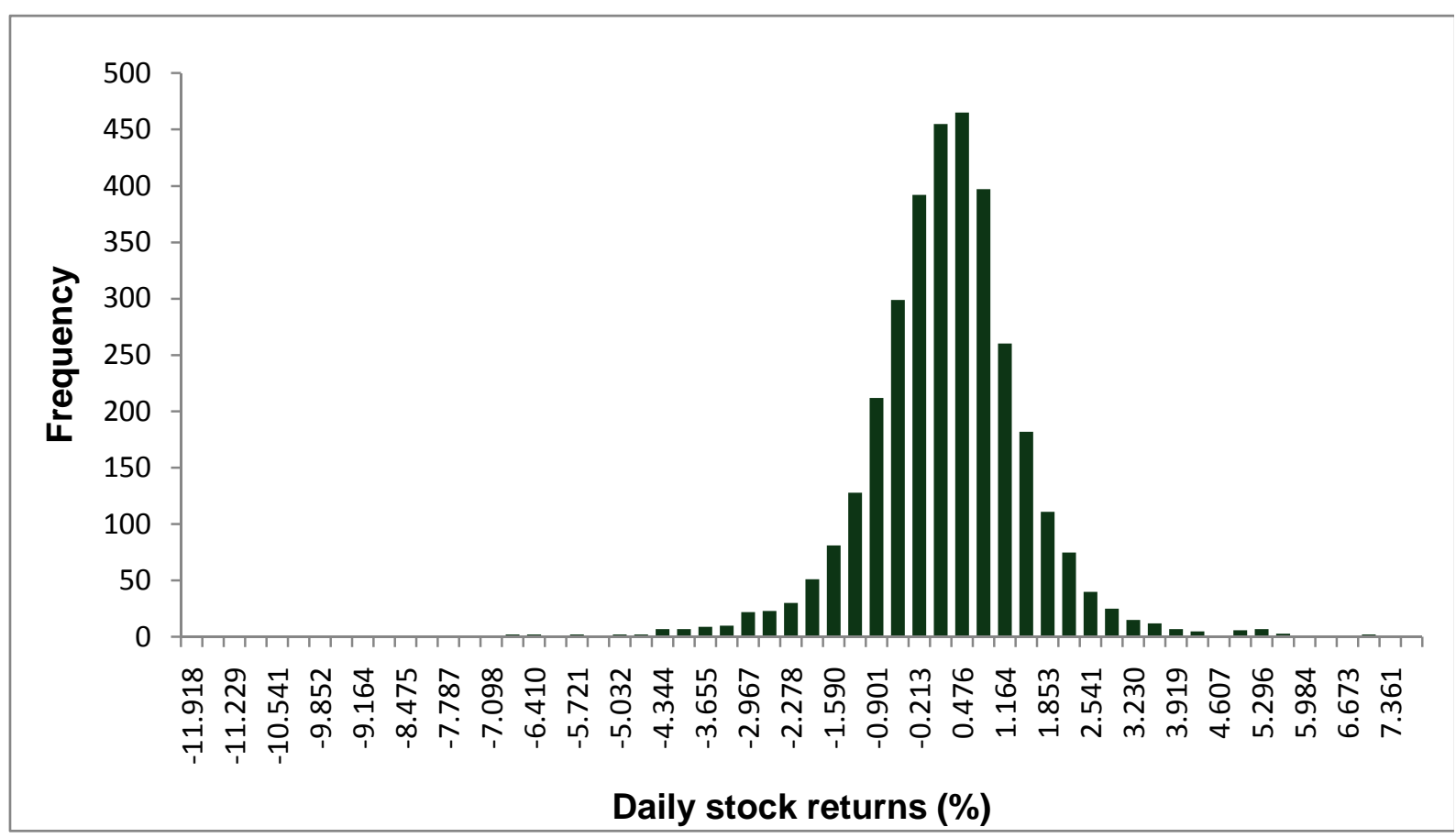

Figure 2: Data distribution of JSE All Share index daily returns for all trading days

$\mathrm{R}_{\mathrm{t}}=\beta_{0}+\beta_{\mathrm{W}} \mathrm{W}_{\mathrm{t}}+\beta_{\mathrm{L}} \mathrm{L}_{\mathrm{t}}+\varepsilon_{\mathrm{t}}$

where

$\mathrm{R}_{\mathrm{t}}$ represents the log return for the JSE All Share Index and $\mathrm{W}_{\mathrm{t}}$ and $\mathrm{L}_{\mathrm{t}}$ are the dummy variables indicating wins or losses. $\beta_{0}$ is a constant, $\beta_{\mathrm{W}}$ and $\beta_{\mathrm{L}}$ are the betas associated with wins and losses, and $\varepsilon_{t}$ is an error term. Matches that are drawn or have no result are treated as the control group.

Kruskal-Wallis $H$-test for the difference between means

According to Cowan (1992) many event study tests rely on parametric test statistics despite the disadvantage that they assume that the probability distribution of returns is normal. In order to ensure statistical reliability the Kruskal-Wallis $H$-test for the difference between means was used as a nonparametric test. Mishra and Smyth (2008) also suggest that the Kruskal-Wallis test is the appropriate test to use when taking into account that the data is not normally distributed. The test allows a check as to whether the mean returns from post-game trading days are equal to the mean return on nongame trading days.

\section{Results}

Results of the Z-tests for the difference in proportions

Table 2 reports the proportion of daily returns after a win (loss) that was greater (less) than the mean return for nongame trading days. The results of the Z-test for the difference in proportions are also presented.

From Table 2 it is evident that after wins in all categories of sport there was a greater proportion of returns that were larger than the unconditional mean return. The results of the Z-test for difference in proportions for wins were 
statistically significant at the $1 \%$ level for the all sports category, 5\% level for the cricket category and 10\% level for the soccer category. The results of rugby wins were, however, not significant. From the table it is also evident that after losses in all categories of sport there was a greater proportion of returns that were smaller than the unconditional return. The results of the Z-test for the difference in proportions for losses were, however, not statistically significant.

\section{Results of the $t$-tests for the difference in means}

Table 3 presents the mean return after a win, draw and loss for all categories of sport and provides the results of the tests for the difference in means.

Table 2: Results of Z-tests for difference in proportions

\begin{tabular}{l|c|c|c|c}
\hline \multicolumn{2}{c|}{} & $\begin{array}{c}\text { Proportion of } \\
\text { returns }> \\
\text { unconditional } \\
\text { mean } \\
\text { (number) }\end{array}$ & $\begin{array}{c}\text { Proportion of } \\
\text { returns }< \\
\text { unconditional } \\
\text { mean } \\
\text { (number) }\end{array}$ & \\
\hline \multirow{2}{*}{ All sports } & Win & $0,594(250)$ & & p-value \\
\cline { 2 - 5 } & Loss & & $0,514(105)$ & $0,005^{* * *}$ \\
\hline \multirow{2}{*}{ Cricket } & Win & $0,571(160)$ & & 0,277 \\
\cline { 2 - 5 } & Loss & & $0,508(58)$ & $0,014^{* *}$ \\
\hline \multirow{2}{*}{ Soccer } & Win & $0,582(46)$ & & 0,370 \\
\cline { 2 - 5 } & Loss & & $0,522(23)$ & $0,087^{*}$ \\
\hline \multirow{2}{*}{ Rugby } & Win & $0,536(44)$ & & 0,351 \\
\cline { 2 - 5 } & Loss & & $0,521(24)$ & 0,289 \\
\hline
\end{tabular}

Notes: The p-values are based on the Z-test for the difference in proportions. * indicates significance at the $10 \%$ level for a one sided test, ${ }^{* *}$ Significance at the $5 \%$ level for a one sided test, *** Significance at the $1 \%$ level for a one sided test.

Figure 3 graphically illustrates a general pattern of mean returns, with mean returns after wins (losses) being generally greater (less) than the unconditional mean return for non-game trading days. This is true for all categories of sport except for soccer, where the mean return for losses was greater than the unconditional mean, although still being less than the mean return after wins.

From Table 3 and Figure 3 it is clear that the mean return for the all sports category was positive after wins as well as after losses. However, as with the study by Ashton et al. (2003), the results were transitive, with the mean return after wins being greater than the mean return after draws, and the mean return after draws being greater than the mean return observed after a loss. When compared to the unconditional mean return on non-game trading days, the mean return was substantially greater after wins and slightly less after losses. The pattern of returns is therefore as expected, with higher returns for wins and lower returns for losses. The results of the $t$-tests for the difference in means were, however, not statistically significant for any of the results classifications for the all sports category.

Table 3: Results of t-tests for the difference in means

\begin{tabular}{l|l|c|c}
\hline \multicolumn{2}{c|}{} & $\begin{array}{c}\text { Mean daily } \\
\text { return (\%) }\end{array}$ & p-value \\
\hline \multirow{4}{*}{ All sports } & Win (441) & 0,115 & 0,223 \\
\cline { 2 - 4 } & Draw (74) & 0,0823 & 0,437 \\
\cline { 2 - 4 } & Loss (204) & 0,00624 & 0,249 \\
\hline \multirow{3}{*}{ Cricket } & Win (280) & 0,0836 & 0,401 \\
\cline { 2 - 4 } & Draw (48) & $-0,1748$ & $0,072^{*}$ \\
\cline { 2 - 4 } & Loss (114) & $-0,0157$ & 0,251 \\
\hline \multirow{3}{*}{ Soccer } & Win (79) & 0,2779 & $0,053^{*}$ \\
\cline { 2 - 4 } & Draw (25) & 0,5979 & $0,064 *$ \\
\cline { 2 - 4 } & Loss (44) & 0,1309 & 0,314 \\
\hline \multirow{2}{*}{ Rugby } & Win (82) & 0,0654 & 0,476 \\
\cline { 2 - 4 } & Draw (1) & $-0,4599$ & $\mathrm{n} / \mathrm{a}$ \\
\cline { 2 - 4 } & Loss (46) & $-0,0585$ & 0,200 \\
\hline
\end{tabular}

Notes: The $p$-values are based on the $t$-test for the differences in means. * indicates significance at the $10 \%$ level for a one sided test.

The mean return after cricket wins was positive and negative after losses. The mean return after cricket wins was greater than the mean return after both draws and losses. However, the mean return after draws was lower than returns after losses. This is contrary to the finding for all sports that returns are transitive. When compared to the unconditional mean return on non-game trading days, the mean return was slightly greater after wins and substantially less after losses. The pattern of returns for cricket is therefore also much as expected, except that the mean return for draws was lower than for losses. The results of the $t$-tests for the difference in means were significant at the $10 \%$ level for draws, but not significant for either wins or losses in the cricket category.

The mean return after soccer matches was positive after wins as well as after losses. The mean return after soccer wins was greater than mean returns after losses. However, once again results are not transitive, as the mean return after draws was greater than the mean return after both wins and losses. When compared to the unconditional mean return on non-game trading days, the mean return was substantially greater after soccer wins and draws and greater even after soccer losses. Although returns after draws were greater than after wins, the expected pattern of returns is much as expected. The results of the $t$-tests for the difference in means were statistically significant at the $10 \%$ level for soccer wins and draws. 


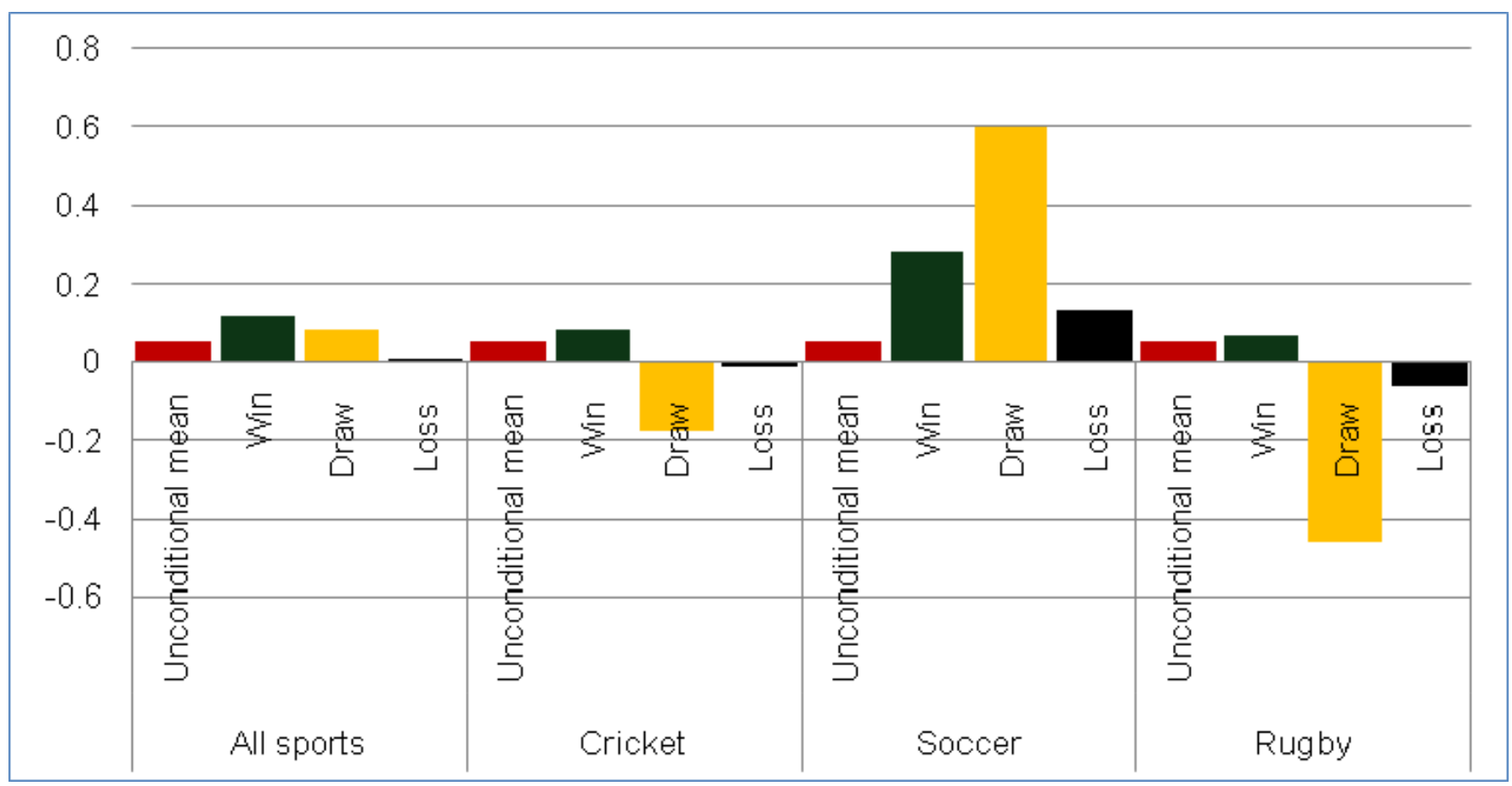

Figure 3: Comparison of mean daily returns

The mean return after rugby matches was positive after wins and negative after losses. The mean return after wins was therefore greater than after losses. The nature of a rugby match is such that it is a rare occurrence for a game to end in a draw. There is therefore only one draw in the period under consideration. This does not lend itself to analysis and was therefore ignored. When compared to the unconditional mean return on non-game trading days, the mean return after rugby wins was only slightly greater but substantially less after losses. The pattern of returns for rugby is therefore as expected. The results of the $t$-tests for the difference in means were, however, not statistically significant for any of the results classifications for rugby.

\section{Results of the dummy-variable regression analysis}

Table 4 provides the summary statistics of the dummyvariable regression analysis for all categories of sport.

Table 4: Summary statistics of the dummy-variable regression analysis

\begin{tabular}{l|l|c}
\hline & \multicolumn{1}{|c|}{ Result } & p-value \\
\hline \multirow{4}{*}{ All sports } & Win (441) & 0,360 \\
\cline { 2 - 3 } & Draw (74) & 0,889 \\
\cline { 2 - 3 } & Loss (204) & 0,412 \\
\hline \multirow{4}{*}{ Cricket } & Win (280) & 0,215 \\
\cline { 2 - 3 } & Draw (48) & 0,306 \\
\cline { 2 - 3 } & Loss (114) & 0,415 \\
\hline \multirow{3}{*}{ Soccer } & Win (79) & 0,142 \\
\cline { 2 - 3 } & Draw (25) & $0,042^{* *}$ \\
\cline { 2 - 3 } & Loss (44) & 0,860 \\
\hline \multirow{2}{*}{ Rugby } & Win (82) & 0,976 \\
\cline { 2 - 3 } & Draw (1) & n/a \\
\cline { 2 - 3 } & Loss (46) & 0,552 \\
\hline
\end{tabular}

Note:** Significance at the $5 \%$ level for a one sided test.
From Table 4 it is clear that the $p$-value results of the dummy-variable regression analysis were not statistically significant for any category of sport, except for soccer draws, which had a statistical significance at the 5\% level.

Results of the Kruskal-Wallis $\mathrm{H}$-test for the Table 5 presents the results of the tests for the difference between means.

The results of the Kruskal-Wallis tests were statistically significant for wins in the all sports, cricket and soccer categories at the $5 \%, 10 \%$ and $10 \%$ levels respectively. The result for rugby wins were, however, not statistically significant. The results were also not statistically significant for either draws or losses in any of the sport categories.

\section{Conclusions}

Table 6 summarizes the results of each statistical test for each category of sport and each result classification.

The results of the statistical tests were somewhat mixed. However, certain tests did provide supporting evidence for each other. The dummy-variable regression analysis did not provide strong evidence to support the hypothesis that stock returns were related to sport results. Only soccer draws were statistically significant at the $5 \%$ level, and this was supported by the $t$-test which was statistically significant at the $10 \%$ level for soccer draws. As can be seen in Table 6, the Z-test for the difference in proportions and the nonparametric Kruskal-Wallis test both provided results for wins in the all sports category that were statistically significant at the $1 \%$ and $5 \%$ level respectively. In addition, the $Z$-test for the difference in proportions, the $t$-test for the difference in means and the Kruskal-Wallis test all provided results for soccer wins that were statistically significant at the $10 \%$ level. Finally, the $Z$-test for difference in 
proportions and the Kruskal-Wallis test both provided results for cricket wins that were statistically significant at the $5 \%$ and $10 \%$ level respectively. Due to the fact that the security market returns are not normally distributed, the most reliable results are those provided by the KruskalWallis test. For this reason the authors regard the results of the Kruskal-Wallis as the true reflection of the relationship between sports results and stock market returns. However, the results of the classical $Z$-test and $t$-test provide evidence to support the findings of the Kruskal-Wallis test.

This research report's findings therefore do not fully concur with previous studies that have found a correlation between sports team performance and stock returns. Ashton et al. (2003) found that good (bad) performances by the English national football team were followed by good (bad) market returns. Edmans et al. (2007) found that negative stock returns in a broad cross-section of markets were associated with losses in football, rugby and basketball matches. Edmans et al. (2007) referred to this as a "loss effect". The findings of this research report therefore differ from these two studies. The results of this research report provide some evidence that wins are followed by greater returns for the all sports, cricket and soccer categories. This could be termed a "win effect". However, the results do not indicate the existence of a "loss effect" for any category of sport. Despite this, the general pattern of returns does indicate that returns are lower than the unconditional return after losses for all categories of sport, despite not being statistically significant. Although the results of individual statistical techniques are mixed, when viewed together there appears to be some evidence to suggest a relationship between positive sporting results and increased returns on the JSE All Share index.

Table 5: Results of the Kruskal-Wallis $\boldsymbol{H}$-test

\begin{tabular}{l|l|c}
\hline & \multicolumn{1}{|c|}{ Result } & $\boldsymbol{p}$-value \\
\hline \multirow{4}{*}{ All sports } & Win (441) & $0,021^{* *}$ \\
\cline { 2 - 3 } & Draw (74) & 0,800 \\
\cline { 2 - 3 } & Loss (204) & 0,606 \\
\hline \multirow{4}{*}{ Cricket } & Win (280) & $0,057^{*}$ \\
\cline { 2 - 3 } & Draw (48) & 0,306 \\
\cline { 2 - 3 } & Loss (114) & 0,713 \\
\hline \multirow{3}{*}{ Soccer } & Win (79) & $0,087^{*}$ \\
\cline { 2 - 3 } & Draw (25) & 0,261 \\
\cline { 2 - 3 } & Loss (44) & 0,931 \\
\hline \multirow{3}{*}{ Rugby } & Win (82) & 0,712 \\
\cline { 2 - 3 } & Draw (1) & n/a \\
\cline { 2 - 3 } & Loss (46) & 0,539 \\
\hline
\end{tabular}

Notes: $p$-values are based on the Kruskal-Wallis test for the difference between two populations * indicates significance at the $10 \%$ level for a one sided test, $* *$ Significance at the $5 \%$ level for a one sided test.

The absence of a "loss effect" and the existence of a moderate "win effect" for South African sports teams are therefore perhaps as a result of lower, rather than higher expectations by supporters. South African supporters are notoriously cynical about the prospects of their sports team performance and therefore if a team loses it does not have a significant negative effect on mood. However, if a team wins, it results in elation and euphoria which is then reflected in stock returns

Table 6: Summary of statistical test results

\begin{tabular}{|c|c|c|c|c|c|}
\hline & & $\begin{array}{c}Z \text {-test: } \\
\text { Proportions }\end{array}$ & $\begin{array}{l}t \text {-test: } \\
\text { Means }\end{array}$ & $\begin{array}{c}\text { Dummy- } \\
\text { variable } \\
\text { regression }\end{array}$ & $\begin{array}{c}\text { Kruskal- } \\
\text { Wallis }\end{array}$ \\
\hline \multirow[t]{3}{*}{$\begin{array}{l}\text { All } \\
\text { sports }\end{array}$} & Win & $1 \%$ & $X$ & $X$ & $5 \%$ \\
\hline & Draw & $X$ & $X$ & $\mathrm{X}$ & X \\
\hline & Loss & $X$ & $\mathrm{X}$ & $X$ & $X$ \\
\hline \multirow[t]{3}{*}{ Cricket } & Win & $5 \%$ & $\mathrm{X}$ & $X$ & $10 \%$ \\
\hline & Draw & $\mathrm{X}$ & $10 \%$ & $X$ & $X$ \\
\hline & Loss & $\mathrm{X}$ & $X$ & $\mathrm{X}$ & $\mathrm{X}$ \\
\hline \multirow[t]{3}{*}{ Soccer } & Win & $10 \%$ & $10 \%$ & $X$ & $10 \%$ \\
\hline & Draw & $\mathrm{X}$ & $10 \%$ & $5 \%$ & $\mathrm{X}$ \\
\hline & Loss & $\mathrm{X}$ & $\mathrm{X}$ & $X$ & $\mathrm{X}$ \\
\hline \multirow[t]{3}{*}{ Rugby } & Win & $\mathrm{X}$ & $X$ & $X$ & $\mathrm{X}$ \\
\hline & Draw & $\mathrm{X}$ & $\mathrm{X}$ & $X$ & $\mathrm{X}$ \\
\hline & Loss & $\mathrm{X}$ & $\mathrm{X}$ & $\mathrm{X}$ & $\mathrm{X}$ \\
\hline
\end{tabular}

A possible reason why the "win effect" is only moderate and not stronger, and the absence of a "loss effect" could be due to the investment structure of the JSE. Firstly, the JSE has a large proportion of international investors holding South African shares. This would lessen any impact that sporting results of South African teams would have on JSE stock prices as foreign investors would not be influenced by these events. Fock et al. (2008) state that a large proportion of shares on many stock exchanges is traded by foreign investors who are arguably not interested in the outcome of a sporting event involving the local country. They therefore argue that the outcomes of such sporting events are unlikely to have an influence on the stock market. They further point out that many of these international investors may actually even be from countries against whom the local international teams are competing. For example, it can reasonably be assumed that many international investors on the JSE are citizens of countries such as England, New Zealand and Australia, traditionally South Africa's greatest opponents in sports such as cricket and rugby. If this is true, it provides one rationale for the absence of a loss effect and the existence of only a moderate win effect. A further reason is the socio-economic situation in South Africa. The majority of South Africa's citizens cannot afford to invest privately on the stock exchange. One could therefore comfortably assume that the majority of investors on the JSE are institutional investors. It is possible that institutional investors may be less inclined to be influenced by psychological factors than private investors. 


\section{Limitations and constraints of this study}

The following factors were constraints in the case of this research report:

- This research report analysed the daily returns on the JSE All Share Index on the first trading day after sports matches. This allowed for returns to be calculated for a full trading and greatly simplified the process of comparison. However, Boyle and Walter (2003) suggest that it might be useful to study intra-day market data in order to determine if there is a more short-lived effect of match results that is not visible in daily data. Fock et al. (2008) indicate that in an event study, the point in time of the event is of immense importance as efficient markets will immediately reflect the event in stock prices. This research report, as well as other studies such as that of Ashton et al. (2003) used the return of the first trading day after a match. The majority of sporting matches are either held on weekends, or the result of the match is only known after the close of trading for that day. However, there are occasions when the result is known before the close of trading on a particular day. An example is a cricket test match or ODI played during the week. If the match ends before the end of trading, then an efficient market would immediately reflect the outcome. If such a match was played in another part of the world such as Australia, the outcome of the match would be known to South African traders relatively early in the trading day due to the great time difference between the two countries. Fock et al. (2008) therefore point out that a result known on the day of the match should already be reflected in the day's closing price and any measurement of the effect of the match results on the next trading day would lead to a distortion of the results. They argue that it would therefore be difficult to assess the effect of these matches without using intra-day trading data.

- Due to South Africa's political history, the country's national sports teams were excluded from participating in international sporting events until readmission in 1992. This was a constraint on this research report as the population of matches was limited to postreadmission. In addition, the JSE All Share index daily returns which were obtained from the McGregor BFA database (2009) only provide data from September 1995. Similar studies conducted in other markets have had access to match results and stock market return data for a longer period and have therefore been able to better investigate a relationship between sports results and stock returns.

- Boyle and Walter (2003) warn that despite the postulated chain of causation running from events such as sporting events to stock prices it would be prudent to remain skeptical about causation. Firstly, they indicate that due to the extremely large number of possible economically neutral events, there is always a possibility that some events will have a statistically significant yet erroneous correlation with stock prices. Secondly, they warn that factors such as sport events could have a statistical association with some other as yet unknown economic factor. Probably the greatest limitation of this research report is the issue of causality.

- Boyle and Walter (2003) also point out that one possible complicating factor in their study is that many matches take place on weekends and the associated market return is therefore calculated for a Monday. This is often termed the "Monday effect", "day-of-theweek effect" or "weekend effect". Mondays are therefore often associated with abnormal returns. The traditional view holds that returns are higher on Fridays and smaller on Mondays. However, recent evidence by Brusa, Lin and Schulman (2005) indicates the existence of a "reverse weekend effect", where returns on Mondays are actually greater than other days of the week. The majority of the matches by South African teams are played either on a Friday, Saturday or Sunday and the daily return for the first trading day after a match is therefore often measured on a Monday. As Edmans et al. (2007) point out, this may lead to the introduction of a spurious day-of-theweek relationship between the results and stock returns. In this research report $59 \%$ of daily returns after a sporting match are calculated on a Monday and, perhaps significantly, when compared to the other four days of trading in the week, the mean return on a Monday is higher than any other day and is more than twice as large as the next highest day. Monday returns following wins are slightly higher than returns on all other Mondays whilst Monday returns after losses are substantially less and are in fact negative. The difference is, however, not statistically significant ( $p$ value 0,140 ) so that we can't reject the null hypothesis of no difference between Monday returns after losses and those of all other Mondays. Although tests show that this effect is not statistically significant, the possible influence of a Monday effect may therefore have an effect on the results of this research report.

- Boyle and Walter (2003) point out that a problem with the way in which results are classified may lead to a distortion of the results of this type of study. If supporters of a sports team expect the team to win a particular match easily, there may be little or no change in their levels of optimism, self-esteem and positive mood if the team does indeed win the match. The reaction to such a match would therefore be neutral and would have no effect on daily returns. This would have what Boyle and Walter (2003) term a downward bias in the returns for matches classified as a win. Following this logic, if the team is not expected to win the match there may be no negative impact on optimism, self-esteem or mood of supporters and the reaction to the match would once again be neutral. Boyle and Walter (2003) state that this could have an upward bias in the returns after matches classified as a loss. Boyle and Walter (2003) correctly point out that it is extremely difficult to test this possibility since this would entail observing supporters' expectations prior to each match. In order to test whether there is indeed a problem with the classification of all games as either 
win (positive) or loss (negative), Boyle and Walter (2003) suggest that the volatility of returns of wins and losses be compared to the volatility of non-game trading day returns which are assumed to be neutral. If there is a problem with the classification, then it would be expected that wins and losses would have a higher measured volatility than returns on all non-game trading days. In order to test this, the standard deviation of returns for wins and losses is compared to the standard deviation of returns on non-game trading days.

The appropriate test to use is the F-test for the differences in variances. The results of the tests are presented in Table 7. The results indicate that there was in fact a difference in volatility in the daily returns after wins and losses compared with the returns on non-game trading days. For the all sports category, the difference in standard deviation was significant at the $1 \%$ level for both wins and losses. For cricket the difference in standard deviation was significant at the $1 \%$ level for wins but insignificant for losses. For soccer the difference in standard deviation was significant at the $5 \%$ level for losses. However, it was insignificant for wins. For rugby the difference in standard deviation was significant at the $10 \%$ level for wins and at the $1 \%$ level for losses. The existence of only a moderate win and loss effect could therefore be due to the misclassification of results as win (positive), loss (negative).

Table 7: South African sports results and stock market volatility

\begin{tabular}{l|l|c|c}
\hline & Result & Standard deviation of daily returns & $p$-value \\
\hline Non-game trading days & & 1,2935 & $0 *$ \\
\hline All sports & Win & 1,5982 & 0,478 \\
& Draw & 1,2171 & 0 *** \\
& Loss & 1,0747 & 0,12 \\
\hline Cricket & Win & 1,748 & 0,126 \\
& Draw & 1,0752 & 0,396 \\
& Loss & 1,153 & $0,024^{* *}$ \\
Soccer & Win & 1,2045 & $0,036^{* *}$ \\
\hline Rugby & Draw & 1,7492 & $0,091^{*}$ \\
& Loss & 1,0084 & $\mathrm{n} / \mathrm{a}$ \\
& Win & 1,2772 & $0,005^{* * *}$ \\
\hline
\end{tabular}

Notes: The $p$-values are based on an $F$-test for differences in variances. The table closely follows the format used by Boyle and Walter (2003). * ,** and $* * *$ indicate significance at $10 \%, 5 \%$ and $1 \%$ level respectively.

\section{References}

Ashton, J.K., Gerrard, B. \& Hudson, R. 2003. 'Economic impact of national sporting success: Evidence from the London Stock Exchange', Applied Economic Letters, 10: 783-785.

Berument, H. \& Ceylan, N.B. \& Gozpinar, R. 2006. 'Performance of soccer on the stock market: Evidence from Turkey’, The Social Science Journal, 43: 695-699.

Berument, H. \& Yucel, E.M. 2005. 'Long live Fenerbahçe: The production boosting effects of football', Journal of Economic Psychology, 26: 842-861.

Boyle, G. \& Walter, B. 2003. 'Reflected glory and failure: International sporting success and the stock market', Applied Financial Economics, 13: 225-235.

Brusa, J., Liu, P. \& Schulman, C. 2005. 'Weekend effect, "reverse" weekend effect and investor trading activities', Journal of Financial Research, 28(4): 591-608.

CricketArchive. 2009. 'South Africa cricket records'. [online]

URL:http://cricketarchive.com/Archive/Records/SouthAfric a/index.html.
Cowan, A.R. 1992. 'Nonparametric event study tests', Review of Quantitative Finance and Accounting, 2: 343-358.

Edmans, A., Garc'ia, D. \& Norli, Ø. 2007. 'Sport sentiment and stock returns', The Journal of Finance, 62(4): 19671997.

Fock, H., Klein, C. \& Zwergel, B. 2008. 'Reconsidering the impact of national soccer results on the FTSE 100'. Applied Economics, 1-8. [online]

URL:http://www.informaworld.com/10.1080/000368408021 12471.

Hirt, E., Zillman, D., Erikson, G. \& Kennedy, C. 1992. 'Costs and benefits of allegiance: Changes in fans' selfascribed competencies after team victory versus defeat', Journal of Personality and Social Psychology, 63: 724-738.

Kaplanski, G. \& Levy, H. 2008. 'Exploitable predictable irrationality: The FIFA World Cup effect on the U.S. stock market', Journal of Financial and Quantitative Analysis, 43(2): 105-122.

Krueger, T.M. \& Kennedy, W.F. 1990. 'An examination of the Super Bowl Stock Market Predictor', The Journal of Finance, 45(2): 691-697. 
Lucey, B.M. 2000. 'Friday the 13th and the philosophical basis of financial economics', Journal of Economics and Finance, 24(3): 294-301.

McGregor BFA. 2009. 'Price data report: All share (J203), McGregor BFA'. [online]

URL:http://secure mcgbfa.com.ez.sun.ac.za/Station/PriceDa ta/PriceDataDetail.aspx?Token=QW\%2fuKvJQ2hmqd9ouT RTvg\%3d\%3d\&PD_0=1\&PD_T2=1\&ClientID=115\&Con Module $=125 \&$ icon $=$ http $\% 3 \mathrm{a} \% 2 \mathrm{f} \% 2$ fsecure.mcgbfa.com.ez. sun.ac.za $\% 2$ fimages $\% 2 \mathrm{f} 1 \times 1$ trans.gif\&iconid=84\&MCGBF ACompaniesID=9447\&InstrumentType $=4 \&$ Ticker $=J 203$.

Mishra, V. \& Smyth, R. 2008. 'An examination of the impact of India's performance in one-day cricket internationals on the Indian stock market.' Johannesburg Department of Economics, Monash University.

SA Rugby. 2009. 'History of the game'. [online] URL:http://www.sarugby.net/default.asp?cId=7535

SAFA. 2009. 'All Bafana Bafana matches'. [online] URL:http:/www.safa net/UserFiles/www.safa.net/Documen ts/ALL\%20BAFANA\%20INTERNATIONAL\%20MATCH ES\%202009\%20Part1.pdf

http://www.safa net/UserFiles/www.safa net/Documents/AL L\%20BAFANA\%20INTERNATIONAL\%20MATCHES\% 202009\%20Part2.4.pdf.

Worthington, A.C. 2007. 'National exuberance: A note on the Melbourne Cup effect in Australian stock returns', Economic Papers, 26(2): 170-179. 